\title{
Shoulder Pain in Wheelchair Basketball Players
}

\author{
Saleky García-Gómez, Rubén Barakat Carballo and Javier Pérez-Tejero* \\ "Sanitas Foundation" Chair for Inclusive Sport Studies, Faculty of Physical Activity and Sports Sciences, AFIPE research group, Universidad Politécnica \\ de Madrid, Spain
}

Submission: October 13, 2020; Published: October 23, 2020

*Corresponding author: Javier Pérez-Tejero, "Sanitas Foundation" Chair for Inclusive Sport Studies, Faculty of Physical Activity and Sports Sciences, Universidad Politécnica de Madrid, Martín Fierro, 7, 28040, Madrid, Spain

\begin{abstract}
Wheelchair basketball (WB) is probably the most popular adapted sports, being shoulder pain (SP) a common situation for WB players, as a consequence of shoulder injuries. SP has been reported to increase with advancing age and years of wheelchair use; however, players with less than 20 years showed increasing index score. For those who use wheelchair for daily activities, SP is more prevalent while developing sport skills (SS) such as rebounding or one-handed long passes. Subjects between 10 and 20 years since injury had higher SP in activities of daily living (ADLs); being necessary to promote shoulder health using specific programs and to minimize the overload of the shoulder complex in WB players.
\end{abstract}

Keywords: Shoulder pain; Evaluation; Wheelchair injuries; Wheelchair athletes; Assessments

Abbreviations: SP: Shoulder Pain; WB: Wheelchair Basketball; ADLs: Activities of Daily Living

\section{Introduction}

Wheelchair basketball (WB) is probably the most popular adapted sport for people with physical disabilities. Shoulder pain (SP) is a common situation among WB players a consequence of shoulder injuries [1,2] such as sprains, strains, tendinitis, bursitis, impingement syndromes and avascular necrosis [3], reporting in the literature SP a range from 14 to 85 percent [4-6] in WB players The exact biomechanical mechanism and its contribution to the increased risk of SP development is largely unknown [7,8]. A few studies support the shoulder as the common site of pain reported by the wheelchair population $[6,8]$. However, it's necessary to address all the aspect related to SP in this population and how SP influences activities of daily living ADLs development, including WB practice and competition. According to different authors, there is association between age and years of wheelchair use with SP [9-11]: also SP during ADLs could be influenced by the age and wheelchair use [12], but it is still unknown if years of injury and years of sport practice could influence in the appearance of SP in WB players. In this regard, it is relevant to investigate how this could affect the development of ADLs and sport practice of the WB players, and also to establish an early recognition of SP to ensure safety, injury prevention, successful sport planning and participation in sport [13].
Shoulder's health evaluations through tools like the "Shoulder Pain Index for WB (SPI-WB)" [14] are useful to assess players' perceptions while performing transfers, ADLs and those sport skills (SS) relate to WB, as shooting, rebounding/ one-handed long passes and other sport situations. According to previous studies, there were no statistical differences for SP related to specific SS according to age, years since injury, years of wheelchair use and years of federated/recreational sport. However, SP presented statistical differences when performing rebounding/one-handed long passes related to daily wheelchair use [12].

\section{Discussion}

SP in wheelchair athletes is a common problem that must be addressed further [15], due to its consequences in personal autonomy, especially in wheelchair users. Previous studies demonstrated the relationship of age with SP $[10,16]$; however, one study explained that SP it's no necessary a consequence of age [17], so discussion is open. It has been reported SP increases with age and years of wheelchair use in the spinal cord injury population, suggesting that SP scores in subjects over 50 years old were over four times higher than those from subjects between 21-30 years old [9]. However, subjects with less than 20 years 
old showed increasing index score, being affected daily activities as sleep. In this line, WB players that also were daily wheelchair users presented more SP scores during specific SS such as rebounding/one-handed long passes. Although, according to the years of wheelchair experience, SP was significantly different for the item related to "put button down shirt and put on pants"; reporting more pain those with age between 10 and 20 years of wheelchair experience.

In this line, previous studies reported that subjects between 10 and 20 years since injury had higher SP in general ADLs. Also, WB players with less than 10 years of experience practicing federated sport [12] presented higher scores for SP. Therefore, WB players that had less sport experience are more predisposed to present SP. In general, SP affect more ADLs than SS [12]. This is relevant information about the characteristics of $S P$ in $W B$ players and how it could affect the ADLs, providing the basis for the need of preventive shoulder health in this population [14], to avoid SP and injuries, optimizing mobility, strength and muscles balances in the joint, minimizing the overload of the shoulder complex in WB athletes. That is way WB players and technical staff should include this type of programs in their daily training routines.

\section{References}

1. Heyward OW, Vegter RJK, de Groot S, Van der Woude (2017) Shoulder complaints in wheelchair athletes: A systematic review. PLoS One 12(11).

2. Ortega-Santiago R, Gonzalez-Aguado AJ, Fernández-de-Las-Penas C, Cleland JA, de-la-Llave-Rincon, et al. (2019) Pressure pain hypersensitivity and referred pain from muscle trigger points in elite male wheelchair basketball players. Braz J Phys Ther 30(18): 008.

3. Nyland J, Robinson K, Caborn D, Knapp E, Brosky T, et al. (1997) Shoulder rotator torque and wheelchair dependence differences of National Wheelchair Basketball Association players. Arch Phys Med Rehabil 78(4): 358-363.

4. Curtis KA, Black K (1999) Shoulder pain in female wheelchair basketball players. J Orthop Sports Phys Ther 29(4): 225-231.

5. Ballinger DA, Rintala DH, Hart KA (2000) The relation of shoulder pain and range-of-motion problems to functional limitations, disability, and perceived health of men with spinal cord injury: a multifaceted longitudinal study. Arch Phys Med Rehabil 81(12): 1575-1581.

6. Samuelsson KA, Tropp H, Gerdle B (2004) Shoulder pain and its consequences in paraplegic spinal cord-injured, wheelchair users. Spinal Cord 42(1): 41-46.

7. Morrow MM, Van Straaten MG, Murthy NS, Braman JP, Zanella E, et al. (2014) Detailed shoulder MRI findings in manual wheelchair users with shoulder pain. BioMed Res Int 769-649.

8. Finley MA, Rodgers MM (2004) Prevalence and identification of shoulder pathology in athletic and nonathletic wheelchair users with shoulder pain: A pilot study. J Rehabil Res Dev 41(3B): 395-402.

9. Curtis KA, Roach KE, Applegate EB (1995) Reliability and validity of the Wheelchair User's Shoulder Pain Index (WUSPI). Paraplegia 33(10): 595-601.

10. Alm M, Saraste H, Norrbrink C (2008) Shoulder pain in persons with thoracic spinal cord injury: prevalence and characteristics. J Rehabil Med 40(4): 277-283.

11. Soo Hoo J (2019) Shoulder Pain and the Weight-bearing Shoulder in the Wheelchair Athlete. Sports Med Arthrosc Rev 27(2): 42-47.

12. García-Gómez S, Pérez-Tejero J (2017) Shoulder pain according to age, wheelchair use and years of injury in wheelchair basketball players. In CIDESD International Congress "Exercise and Health, Sports and Human Development", Évora, Portugal, 11 - 12 November 2016. Motricidade 13(1): 117

13. Dutton RA (2019) Medical and Musculoskeletal Concerns for the Wheelchair Athlete: A Review of Preventative Strategies. Curr Sports Med Rep 18(1): 9-16.

14. García-Gómez S, Pérez-Tejero J, Hoozemans M, Barakat R (2019) Effect of a Home-based Exercise Program on Shoulder Pain and Range of Motion in Elite Wheelchair Basketball Players: A Non-Randomized Controlled Trial. Sports $7(8)$.

15. Riley AH, Callahan C (2019) Shoulder Rehabilitation Protocol and Equipment Fit Recommendations for the Wheelchair Sport Athlete with Shoulder Pain. Sports Med Arthrosc Rev 27(2): 67-72.

16. Fullerton HD, Borckardt JJ, Alfano AP (2003) Shoulder pain: a comparison of wheelchair athletes and nonathletic wheelchair users. Med Sci Sports Exerc 35(12): 1958-1961.

17. Wessels Kg K, Brown JL, Ebersole KT, Sosnoff JJ (2013) Sex, shoulder pain, and range of motion in manual wheelchair users. J Rehabil Res Dev 50(3): 351-356.

\section{Your next submission with Juniper Publishers will reach you the below assets}

- Quality Editorial service

- Swift Peer Review

- Reprints availability

- E-prints Service

- Manuscript Podcast for convenient understanding

- Global attainment for your research

- Manuscript accessibility in different formats

( Pdf, E-pub, Full Text, Audio)

- Unceasing customer service

Track the below URL for one-step submission https://juniperpublishers.com/online-submission.php 